\section{MR. BATES'S ADDRESS TO THE ENTOMOLOGICAL SOCIETY}

$\mathrm{IN}$ printing the following extracts from the address delivered to 1 the Entomological Society on the 24 th ult. by the President, Mr. H.W. Bates, we must express our regret that we cannot find space for the insertion of the whole of that able and interesting (liscourse.

Referring to the "Transactions" of the Society, Mr. Bates remarked:-The volume for the past year comprises twentyseven memoirs, of which twenty-five belong to the department of systematic or descriptive Entomology, and two only-welcome contributions from Mr. Jenner Weir and Mr. Butler, on the selection of insects as food by insectivorous animals-to other branches of the science. To those who might object that too large a share of our work is occupied by mere descriptions, I would remark that many original and valuable observations on relationships, geographical distribution, and other deeply interesting philosophical questions, are contained in some of our descriptive papers. In fact, it is not at all a necessary consequence that a descriptive treatise should be nothing more than a string of dry definitions. It will become, I hope, more and more the practice of entomologists to give, together with their descriptions, the new data on relationships, distribution, comparison of faunas, \&c., which the handling of such subjects most usually brings forth.

In speaking of the contributions of importance which have been made to the science in this country outside the Entomological Society, the President alluded to the examination by $\mathbf{M r}$. Wollaston of the largest collection of insects which has yet been made in St. Helena. This suggested the following observations : As you are aware, the great interest which attaches to the fauna and flora of oceanic islands arises from the problems involved in the modes in which they obtained their species of animals and plants, and those are rendered more complicated by the existence on some island of anomalous forms, representative, it is considered, of types ages ago extinct on continents. Such islands, however, differ greatly from each other as to degree of peculiarity in their productions ; and it often happens that species identical, or nearly so, with those found in the nearest continent form nearly the whole of their present inhabitants. Thus the investigation of the origin of their faunas and floras is necessarily excecdingly complex. Geology has to be invoked to ascertain whether the islands are of recent or ancient elevation above the sea-surface, and whether the supposition is admissible of a recent connection with the nearest continental land Oceanic hydrography, deep-sea soundings, and the force and direction of currents and winds, have to be studied in reference to the depth of the surrounding seas; for these must all be taken into consideration in discussions on the probable derivation of the curious mixture of forms which is often found on these isolated spots. On the other hand, it must be noted that the fauna and flora themselves throw light on the geographical and geological relations of the islands to the nearest land. In fact, the classification of islands into oceanic and continental, is founded quite as much on resemblance or difference in organic productions, between islands and the mainland, as on relative proximity. Thus Great Britain is classed as a continental islancl, quite as much because its fauna and flora are nearly identical with those of continental Europe as because it is separated only by a shallow sea, and is now known to have been actually connected in recent geological times. In these investigations entomology is now generally admitted to have great importance, owing to the large number and variety of species which it offers, as elements in the elaborate comparisons which have to be instituted.

The following remarks well illustrate the high scientific importance of studying the geographical distribution of insect life :The idea of the value of localities in connection with specimens or species, with some entomologists, I am afraid does not reach very far. They like to know in what countries the different forms are found, and perhaps, as in French collections, show the distribution by writing the specific names in their cabinets on labels coloured according to the part of the world the species inhabit ; the primary divisions of the world, as Europe, North and South America, Africa, Australia, perlaps the West Indies, and so forth, being considered sufficient. This brings out the leading facts of distribution very well, such as the restriction of many genera and groups of genera to each of the great divisions, and the distinctive facies which all the products from one region possess; but we seldom see it carried further, and it remains a pretty association of geography with natural history, and no more. Results infinitely more suggestive are brought about if the student labels each specimen with its locality, instead of recording it on the ticket which bears the specific name placed below all the specimens, and if he is fortunate enough to be able to amass a large suite of specimens, accurately so ticketecl, of genera abounding in local varieties and closely-allied species, indications of the conditions under which varieties, Iocal races, and perhaps species, are formed in nature, are revealed by this method, and a field of investigation is opened which connects the study of a few insect species with some of the most difficult problems that are now engaging the attention of philosophers. The most conmon event that happens, when a student works at a series of species in this way, is the discovery that even the most constant species vary in some parts of their area of distribution; the next, that a small well-marked difference in a species is generally a local difference, and embraces all the individuals of the district in which it occurs. As the collection increases, further curious facts come out. It is found, for instance, that some highly-variable species give rise to one set of varieties in one area, another distinctly cifferent set in another area, and so on; and further, that in some areas one, or perhaps more, of these variations will be better marked than, and preponderate in number over, the other varieties of the same species. Still further, it is found that in some districts one sych variety alone occurs, having apparently prevailed over all the others. To be properly impressed, how. ever, with the great truth and reality of these facts, the student should himself have travelled as an entomological collector over an extent of country embraced by many local varieties of variable species; otherwise his attention will not be sufficiently excited to the curious facts nature presents to him, and he will not talse the trouble to amass and obtain the exact localities of numerous specimens of common variable species. Perhaps the most important result of this attention to distribution of varieties is, that a fine gradation of forms or degrees of variation will be found, from the "sport" or variety, such as is liable to be pro. duced in the same brood, to the well-segregated race living in company with another race referable to the same stock. As such, most authors, perhaps rightly, consider these latter as good and true species; and thus the formation of species out of mere variations is illustrated by the facts of geographical distribution.

But it is not this branch of the subject with which we are so much concerned, when we wish to compare the productions of the different Andean valleys and their vertical ranges, as that relating to the nature of barriers to distribution. It has been received as a principle in zoological and botanical geography, that grand physical barriers, such as mountain ranges, form an impas. sable limit to the faunas and floras of the plains on each side of them. It is repeated, in almost every manual of physical geography, after Humboldt, who, I believe, was the originator of the statement, that the species are all different on the two sides of the Andes of South America. Such a fact, if well established, would be interesting in many ways. First, it would throw light on the geology of the country, as proving that the Andes must have existed as a ridge, sufficiently lofty to prevent the creatures of the plains crossing it, before the origin of the species which now people the plains on each sicle. Now, it is possible that this broad and important generalisation may have been made on a too slender foundation of facts. Of course, in those parts of the Pacific coast-region (two-thirds of the whole line within the tropics), where the conditions of soil, climate, and vegetation are totally different on the two sides of the Andes, no community of species is possible. A lofty mountain barrier would be here unnecessary, for a few steps of level road, in many parts of the world, would suffice to bring the traveller from the domain of one fauna to that of another-for instance, from an arid plain to a luxuriant forest along some river-valley. This would be a difference of "station," and not of area of distribution,--a distinction long ago recognised in Botany. The question is, then, limited to this: In those parts of the Pacific coast-region, such as Guayaquil, where a humid forest-country exists on both sides of the Cordillera, are the species of the two sides entirely distinct? This would test the efficacy of mountain-barriers better than almost any other case. For the species, at least of insects, which inhabit humid forests near the equator, are probably unable to exist at a higher altitude than 4,000 or 5,000 feet, and no pass over the Cordillera exists of half this depression, throughout the whole line of the Andes from Bolivia to the Isthmus of Darien. The species could not voluntarily pass over, nor by 
gradual migration along the coast could they well double the end of the chain near the mouths of the Atrato and Magdalena, and so pass to the eastern sicle; for the Sierra Nevada bars the way.

Insects, I believe, would offer better data in discussing this question of barriers than almost any other group of land animals, or than plants; they are more limited in range than the species of birds, afford a much larger body of facts than reptiles, mammals and shells, and are not so much subject to accidental means of transportation as plants. But although many Entomological collectors have visited Guayaquil and the Cordillera, we have no published lists and no authentic information about localities. Mr. Buckley's journey offers us, then, the chance of obtaining the details so much required, since he collected assiduously all the way up from the level of the sea to the edge of the snow, and the same conversely on the opposite side, writing the locality on the envelope of every specimen.

$I$ am inclined to think that the efficacy of physical or geographical barriers in limiting the distribution of alrimals and plants has been much over-estimated, and that this circumstance has vitiated much of the reasoning that has been employed in discussing various difficult problems in Natural History. By physical barriers, of course, are meant barriers of the jnorganic world, such as a continuous mountain-range with regard to species of the plains and, conversely, a continuous plain with regard to species of the mountains (e. g. Parnassius, Erebia, Oreina, Nebria, \&c.) The sea is thus a barrier to land-species, a water-shed to freshwater species, a continuous tract of forest to species of the savannah or steppe, and so on. Barriers of the organic world, which of course are "physical" also, are quite a different set of agencies. They are the hindrances offered to the dissemination of a species by other species already in full possession of the domain and well adjusted to its conditions by constitution and habits. To this may be added the limitations to distribution observable without any physical obstacle being perceptible. There are certain classes of facts which seem to me to indicate that these less obvious kinds of barrier are far more effective than those more imposing ones of mountain, desert, sea, and so forth.

One set of these facts is exemplified by the well-known case of distribution of insects between the east and west in the southern part of our own island. I am not aware that comparative lists have yet been published; but it will not be disputed that many hundreds of species of Coleoptera, for instance, are known in the east, many of them abundant, which are totally unknown in the west, and a smaller number are known in the west which are not found in the east. In In cases like these a difference of climate may be the cause of the limitation. But there is another set of facts requiring quite a clifferent explanation : this is the limited ranges of closely-allied species in the plains of Tropical America. I have already elsewhere recorded the fact that, in the forest plains of the Amazons, where there are no differences of level worth mentioning, and no physical barriers, the species of a large number of genera are changed from one locality to another, not more than 200 or 300 miles apart. This is most distinctly marked on the Upper Amazons, where the country may be mapped out into areas of a few hundred square miles each, every one containing numerous species of such genera as Ithomia, Melinæa, Eubagis, Doryphora, Erotylus, \&c., \&c., allied to but quite distinct from their representatives in the others. From what $I$ have seen of Mr. Buckley's collections on the eastern side of the Andes, I think the same limitation of areas must occur there also; and judging from the few species I know as coming undoubtedly from the Guayaquil side of the Cordillera, the butterfly faunas of these areas in the uniform country of the east are pretty nearly as distinct from each other as the species east of the Andes are distinct from those west of the mountains. We here again feel the want of facts, such as Mr. Buckley collected, but which have not yet been published, to teach us exactly what species are found east and what west of the mountains, and how the great multitude of closely-allied species are distributed in the narrow tract explored on the east. My own observations in the level plain, a few hundred miles further east, show distinctly, however, that the most effective possible barriers are there opposed to the spread of hosts of species without any physical barrier which is perceptible by our senses. The explanation of the fact, I believe, is this, that there really are subtle differences of physical conditions from place to place, even in a uniform region; slight differences in soil, humidity, succulence of foliage, and so forth, which require in each a re-adjustment of the constitution of any new immigrants from adjoining areas; but that each area being kept well stocked with allied species already adjusted to its minute conditions, such migration rarely occurs. Thus a limit is put to the spread of species by species themselves, which produces similar results on the actual distribution of forms throughout the world, to those produced by mighty physical barriers such as the Andes.

There is yet one other consideration remaining. If these bariers are not required to explain the limitation of faunas, it does not follow that they do not act as barriers all the same; but it is, I think, difficult to prove it. If 1,200 miles of sea do not form a sufficient barrier against the stocking of the Azores with insects from Western Europe, $I$ do not think sixty miles of mountain should be assumed to prevent for tens of thousands of years, the transport of species, in the egg state, by birds or currents of air, from one side to the other. I may add, in conclusion, that if the efficacy of barriers of this nature has been overrated, some important conclusions regarding changes on the earth's surface will have to be reconsidered ; such, for instance, as that of the extension of a glacial epoch over nearly the whole earth - a hypothesis conceived by Darwin to explain the existence of the same genera and sometimes the some species in high latitudes, both in the northern and southern hemisphere, whilst absent from the intervening zones. I believe that, with some very obvious exceptions, such as Mammals and Batrachians, there can be no limit placed as to the dissemination of a species, provided there are unoccupied areas suitable to it, in any part of the earth, and provided also time sufficient be allowed for the process.

\section{THE GRESHAM LECTURES}

TWO lectures were delivered in Gresham College on the evenings of the $14^{\text {th }}$ and $15^{\text {th }}$ January, by Dr. Symes Thompson, the Gresham Professor of Medicine.

The first of these lectures embraced a theme admirably adapted to fulfil the popular object with whicin this City professorship has been established, and as eminently suited to the present season: it treated of "Catching Cold."

The Professor first described, by reference to large drawings, the structure and arrangement of the parts concerned in the disorder-laying open the arcana of the nose, frontal sinuses, throat, voice-box, and chest, and showing the intimate relations by which these parts are connected, and the way in which modern science has found means to bring their inmost recesses under observation, and contrasting the precise knowledge of the present period with the ante-Schneider days, when all catarrhal defluxions were held to be outpourings of the brain. It was demonstrated that the ordinary cold is simply, in the first instance, congestion of the warm, moist, blood-charged membrane, which lines all these cavities and is continuous throughout the series of them; but that this congestion is apt to pass on, under unfavourable circumstances, to inflammation, and to consequent derangement of structure. The congestion merely means that more blood is thrust upon, and retained in, the minute channels and vessels of the membrane, than those channels and vessels can healthily accommodate. The first cause of this forced engorgement is that cold is extensively applied to the internal skin, which then, under the constringing and contracting influence, drives its own blood out, partly into these surcharged tracts of mucous membrane. The injurious effect known as "cold" is now sure to be realised if this external chill is experienced when the general system is weakened by exhaustion. It is also, in some persons, more apt to be produced at certain regular periods.

The prevention of colds is to be accomplished by keeping the skin in a healthy and vigorous state, so that it may at once resume its proper and normal condition when chills have been suddenly applied to it : then the internal congestions are avoided or removed simultaneously with the external contraction and stagnation. The habitual use of cold batling in the early morning is one very powerful means to this end : it trains the vessels of the skin to rise vigorously into renewed action after the application of a chill. The relaxing influence of over-heated apartments should be avoided, because that saps the power of vigorous reaction; but, in cold weather, the utmost care should be taken to have the entire skin efficiently protected by warm clothing. The powers of the system in periods prone to the production of colds, and most especially when the temperature of the external 